\title{
NMMP1, a Matrix Metalloprotease in Nicotiana benthamiana Has a Role in Protection against Bacterial Infection
}

\author{
Sora Kang ${ }^{1}$, Sang-Keun $\mathrm{Oh}^{2}$, Jong-Joo Kim ${ }^{1}$, Doil Choi ${ }^{2 *}$ and Kwang-Hyun Baek ${ }^{1 *}$ \\ ${ }^{1}$ School of Biotechnology, Yeungnam University, Gyeongsan 712-749, Korea \\ ${ }^{2}$ Department of Plant Sciences, Seoul National University, Seoul 151-742, Korea \\ (Received on October 28, 2010; Accepted on November 19, 2010)
}

Plant matrix metalloproteases (MMPs) are a family of apoplastic metalloproteases closely related to human matrilysins. Up-regulation of Nicotiana benthamiana matrix metalloprotease 1 (NMMP1) expression by treatment with pathogens, ethephon and aging indicates that the gene is related to plant defense and the aging process through ethylene signaling. NMMP1 expression was higher than in normal growth leaves following infection with an incompatible pathogen Pseudomonas syringae pv. tomato $\mathrm{T} 1$ or a compatible pathogen $P$. syringae pv. tabaci and in aged leaves. Transient overexpression of NMMP1 in $N$. benthamiana leaves lowered the growth of $P$. syringae pv. tabaci. However, NMMP1-silenced leaves showed increased growth of $P$. syringae pv. tabaci. These data strongly suggest that $N M M P 1$ in $N$. benthamiana is a defense related gene, which is positively regulated by ethylene.

Keywords : Defense, matrix metalloprotease, overexpression, pathogen, virus-induced gene silencing (VIGS)

Plants are equipped with a large proteolytic machinery for housekeeping to remove non-functional proteins and to release amino acids for recycling (Baek and Choi, 2008; van der Hoorn, 2008). Plant proteases are an essential factor for regulating growth, development, stress responses, and pathogen defense (Coffeen and Wolpert, 2004; Dreher and Callis, 2007; van der Hoorn and Jones, 2004). Hundreds of genes encoding proteases have been identified. For example, at least 723 and 955 putative protease genes within the Arabidopsis and Populus genomes have been identified, respectively (Garcia-Lorenzo et al., 2006). Among the proteases, matrixins or matrix metallopeptidases are the proteases that degrade and remodel structural proteins within

\footnotetext{
*Corresponding authors.

DI Choi

Phone) +82-2-880-4568, FAX) +82-2-873-2056

E-mail)doil@snu.ac.kr

KH Baek

Phone) +82-53-810-302, FAX) +82-53-810-4769

E-mail)khbaek@ynu.ac.kr
}

the extracellular matrix (ECM) (Barett et al., 2004). As a complex structural entity surrounding and supporting cells, the ECM is composed of structural proteins, specialized proteins, and proteoglycans (Roberts, 1994).

Matrixins belong to the M10A family in Clan MA(M), according to the MEROPS database system (Rawlings et al., 2010). The M10A family of vertebrate matrixins includes a number of proteases, such as matrilysins, collagenases, gelatinases and stromalysins (Barrett et al., 2004). Matrixins, synthesized as prepro-enzymes, target ECM using a signal peptide (Nagase and Woessner, 1999). Activation of the pro-matrixins is achieved by in vivo proteases or by mercurial compounds and reactive oxygen in vitro (Nagase and Woessner, 1999). In animal systems, matrixins are involved in development, embryogenesis, organ morphogenesis, and wound healing, as well as in pathological processes such as cancer and arthritis (Barett et al., 2004).

Several matrixins have been isolated from plants, including soybean (Graham et al., 1991; Liu et al., 2001; McGeehan et al., 1992; Pak et al., 1997), Arabidopsis (Maidment et al., 1999; Golldack et al., 2002), cucumber (Delorme et al., 2000), alfalfa (Combier et al., 2007), Pinus taeda (Ratnaparkhe et al., 2009), and Nicotiana tabacum (Schiermeyer, 2009). Matrixins have zinc at their catalytic center and are sensitive to EDTA (McGeehan et al., 1992). The first matrixin isolated from a plant was SMEP-1 (soybean metalloendoproteinase-1) from soybean leaves, which has both structural and biochemical similarities with vertebrate matrixins (Graham et al., 1991; McGeehan et al., 1992). GmMMP2, a second matrixin from soybean is upregulated during infection by an oomycete pathogen Phytophthora sojae or the bacterial pathogen $P$. syringae pv. glycinae (Liu et al., 2001). Up-regulation of GmMMP2 by pathogens might indicate involvement of the gene in defense; however, GmMMP2is not induced by the classical pathogen-induced signaling molecules, such as salicylic acid and jasmonic acid (Liu et al., 2001). Gain- or loss-offunction studies of MtMMPL1, a Medicago truncatula matrixin, demonstrated that the gene is a novel and specific marker for root and nodule infection by Sinorhizobium meliloti and regulates Rhizobia infections (Combier et al., 
2007). NtMMP1, the first tobacco matrixin gene, is constitutively expressed at a low level but up-regulated by bacterial pathogen infection (Schiermeyer et al., 2009). All of these studies strongly suggest that plant matrixins are involved in pathogen defense mechanisms.

Using a cDNA bioinformatics analysis of Nicotiana benthamiana, we isolated $N M M P 1$, the first ECM metalloprotease 1 gene isolated from $N$. benthamiana. We investigated the role and regulation of NMMP1 in response to compatible and incompatible pathogens by employing gainor loss-of-function studies.

\section{Materials and Methods}

Growth conditions for $\boldsymbol{N}$. benthamiana and bacterial pathogens. $N$. benthamiana seeds were germinated in commercially available horticultural crop soil and grown in a controlled environment room under a regime of $16 / 8 \mathrm{~h}$ light/dark at $23 \pm 2^{\circ} \mathrm{C}$. Six-week-old $N$. benthamiana plants were used for the various pathogen or chemical treatments. All chemicals were purchased from Sigma-Aldrich (St. Louis, MO, USA) or from Duchefa (Haarlem, The Netherlands).

The inoculated bacterial pathogens included Pseudomonas syringe pv. tomato T1 (PST1), P. syringe pv. tabaci (Psta), and P. syringe pv. tabaci 11528 (Psta 11528). Psta 11528 is resistant to rifampicin at $100 \mathrm{mg} / \mathrm{mL}$. Bacteria were grown at $28^{\circ} \mathrm{C}$ in King's B media containing (per liter): $20 \mathrm{~g}$ proteose peptone no. 3, $10 \mathrm{~mL}$ glycerol, $1.5 \mathrm{~g}$ $\mathrm{K}_{2} \mathrm{HPO}_{4}$, and $1.5 \mathrm{~g} \mathrm{MgSO}_{4}$. For bacterial infection, an overnight culture of bacterial cells was harvested at $4^{\circ} \mathrm{C}$ and 4,000 rpm for $10 \mathrm{~min}$ and re-suspended in sterile $10 \mathrm{mM}$ $\mathrm{MgCl}_{2}$ at a concentration of $0.01,0.05$, or $0.1 \mathrm{OD}_{600 \mathrm{~mm}}$.

NMMP1 isolation and RNA analysis. Total RNA samples were extracted from the leaves of $N$. benthamiana using TRI reagent (MRC, Cincinnati, OH, USA), according to the manufacturer's instructions. The quality of the total RNA was determined on $1.2 \%$ agar gels, and the amounts were quantified by a spectrophotometer (ASP-3700, ACTGene, Piscataway, NJ, USA). Complementary DNA was constructed with an RT-PCR kit using oligo dT supplied by Elpis Biotech Inc. (Daejeon, Korea). N. benthamiana matrixin genes were searched by comparing the matrixin genes in Arabidopsis with the sequences of $N$. tabacum cDNAs stored at Gene index (http://compbio.dfci.harvard. edu/tgi/plant.html), and, finally, EST no. TC7253 was identified as a matrixin gene in tobacco. The $N$. benthamiana matrixin gene was isolated by PCR with the forward primer, 5'-CACAGACTTTAAAGCTCAAA TAC3', and the reverse primer, 5'-GATTTATCTGTCTCAAAATAGAG-3'. The PCR was performed in a $20 \mathrm{~mL}$ volume containing $100 \mathrm{nM}$ of primers, $2 \mathrm{~mL}$ of cDNA as the template, and 2 units of Taq polymerase (Elpis Biotech) using a PCR program composed of $94^{\circ} \mathrm{C}$ for 2 min followed by 32 cycles of denaturation at $94^{\circ} \mathrm{C}$ for $1 \mathrm{~min}$, annealing at $52^{\circ} \mathrm{C}$ for $40 \mathrm{~s}$, and an extension at $72^{\circ} \mathrm{C}$ for $3 \mathrm{~min}$. An approximate $1.4 \mathrm{~kb}$ PCR product was visualized by $1.2 \%$ agarose gel electrophoresis, and cloned into the pCR2.1TOPO vector using a Topo TA cloning kit (Invitrogen, Carlsbad, CA, USA). The cloned gene was finally identified as a matrixin in $N$. benthamiana by sequencing at the NICEM sequencing facility (Seoul National University, Seoul, Korea). Sequence data have been deposited at the NCBI database under accession number GU441835.

Defense signaling molecule treatments. Defense signaling molecules and bacterial pathogens were inoculated into the leaf mesophyll tissues using an 1-mL needleless syringe. Chemicals were prepared at concentrations of 0.1 $\mathrm{mM}$ salicylic acid (SA), $0.1 \mathrm{mM}$ methyl jasmonate (MJ), or $5 \mathrm{mM}$ ethephone (ET). Compatible Psta and Psta 11528 pathogens, and an incompatible $P S T 1$ pathogen (Almeida et al., 2009) were grown in King's B liquid media at $28^{\circ} \mathrm{C}$ and adjusted to $0.01,0.05$, or $0.1 \mathrm{OD}_{600 \mathrm{~nm}}$ in sterile $10 \mathrm{mM}$ $\mathrm{MgCl}_{2}$ solution. Leaves were harvested at 0 to $24 \mathrm{~h}$ after the treatments, and total RNA was extracted or frozen immediately in liquid nitrogen and stored at $-80^{\circ} \mathrm{C}$ before being used for RNA extraction.

Transient overexpression of NMMP1 by Agrobacterium infiltration. The cloned $N M M P 1$ gene was digested with $X b a \mathrm{I}-$ BamHI and integrated into the 23001 plant gene expression vector. The 23001 plant gene expression vector was a kind gift from Dr. SY Kwon at KRIBB, which was made by inserting a 35S CaMV promoter and connecting a NOS terminator in the pCAMBIA2300 vector. The recombinant vector or 23001 vector insert was transferred to $A$. tumefaciens strain EHA105 using the freeze-thaw method described by An et al. (1987). A. tumefaciens transformed with NMMP1 in the 23001 vector or only the 23001 vector was grown in YEP media enriched with rifampicin $(50 \mu \mathrm{g} /$ $\mathrm{mL})$ and kanamycin $(50 \mu \mathrm{g} / \mathrm{mL})$ at $28^{\circ} \mathrm{C}$. The overnight culture of Agrobacterium transformants was collected by centrifugation at $6,000 \mathrm{~g}$ for $10 \mathrm{~min}$ at $4^{\circ} \mathrm{C}$, resuspended in $10 \mathrm{mM} \mathrm{MgCl}_{2}$ at $0.5 \mathrm{~A}_{600}$, acetosyringone was added at 150 $\mu \mathrm{M} / \mathrm{mL}$, and the culture was incubated at $22^{\circ} \mathrm{C}$ for $4 \mathrm{hrs}$. The incubated Agrobacterium transformants were inoculated into 6-week-old $N$. benthamiana leaves. Transient NMMP1 over-expression was detected by extracting total RNAs, synthesizing cDNAs, and performing RT-PCRs with the primer set (forward: 5'-GCAAAACTTCAACCTCAACACC-3' and reverse: 5'-TTTGCAAGCTCCACTCTTCG-3'). PCRs were conducted in a volume of $20 \mu \mathrm{L}$ 


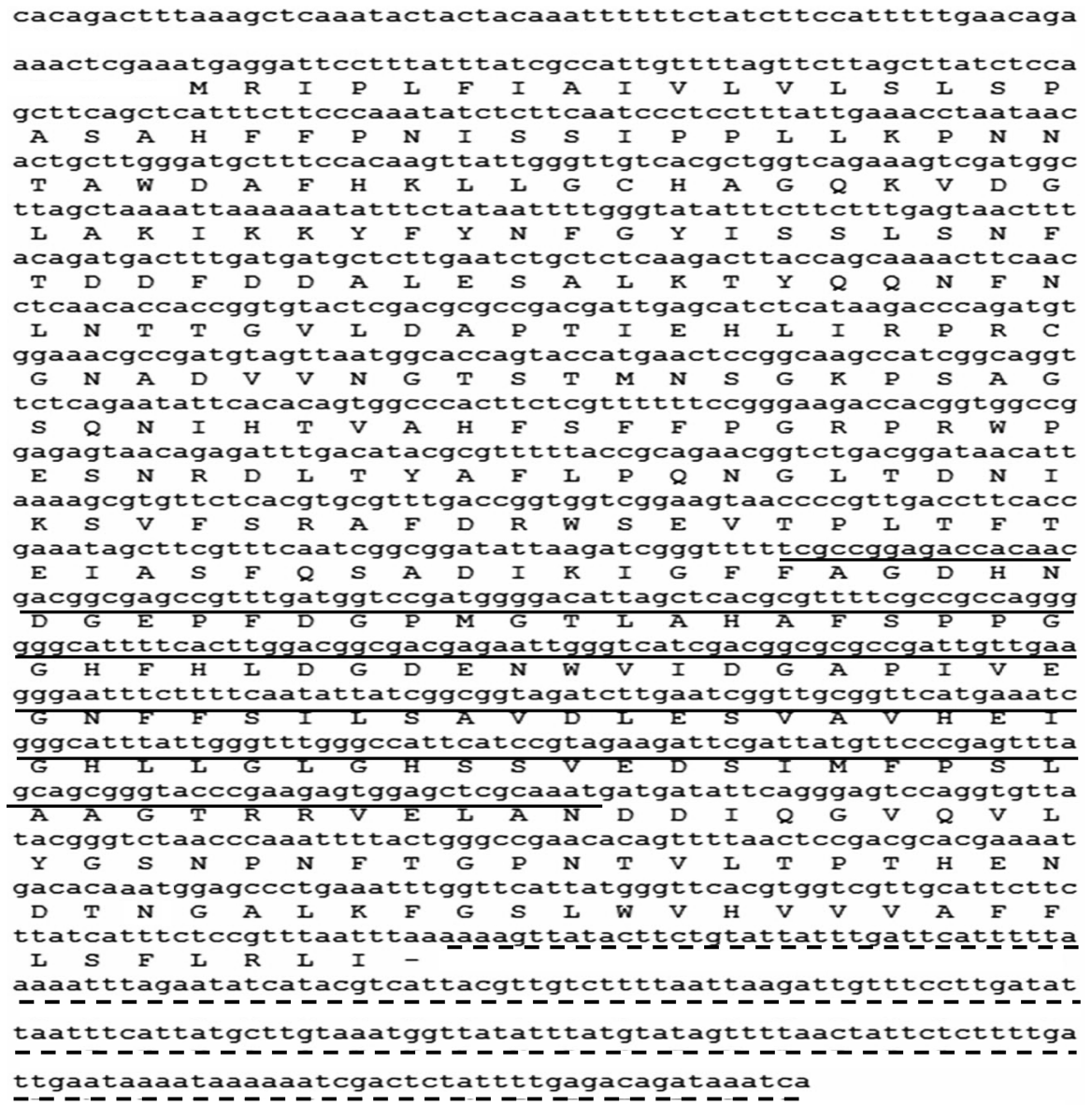

Fig. 1. The nucleotide and amino acid sequence of the Nicotiana benthamiana matrix metalloprotease 1 (NMMP1) gene. The underlined and dotted underlined region were used for building the NMMP1-M or NMMP1-3UTR gene silencing constructs, respectively.

containing $100 \mathrm{nM}$ of primers, $1 \mu \mathrm{L}$ of cDNA as the template, and 2 units of Taq polymerase (Elpis Biotech, Korea). The PCR program was composed of $94^{\circ} \mathrm{C}$ for $3 \mathrm{~min}$ followed by 28 cycles of denaturation at $94^{\circ} \mathrm{C}$ for $1 \mathrm{~min}$, annealing at $52^{\circ} \mathrm{C}$ for $40 \mathrm{~s}$, and extension at $72^{\circ} \mathrm{C}$ for $2 \mathrm{~min}$. The PCR product was visualized on $1.2 \%$ agarose gel electrophoresis.

Virus-induced gene silencing (VIGS) of NMMP1 in $N$. benthamiana. A stock solution of A. tumefaciens strain GV2260 was prepared for VIGS as described by Liu et al. (2002). Two VIGS constructs were prepared, such as $N M M P 1-M$ (targeting the NMMP1 Zn-metalloprotease conserved region) and NMMP1-3UTR (targeting the NMMP1 3 '-untranslated region). PCRs were performed with specific primers to make the two constructs. The primer sets used to amplify NMMP1-M (the underlined region in Fig. 1) were the forward primer 5'-CGGAATTCGGAAGTAACCCCGTTGAC-3' and the reverse primer 5'-TCCGCTCGAGATTTGCGAGCTCCACTC-3'. The NMMP1-3UTR fragment (the dotted underlined region in Fig. 1) was amplified using the forward primer 5'-CGGAATTCAAAAGTTATACTTCTGTATTA-3' and the reverse primer 5'-TCCGCTCGAGAAAAGTTATACTTCTG-3'. The amplified fragments were digested with EcoRI and XhoI and ligated into TRV2 plasmids. A. tumefaciens was transformed with TRV2 plasmids containing the genes of green fluorescent protein $(G F P)$, pepper phytoene synthase (CaPDS) (Chung et al., 2004), NMMP1-M, or NMMP1-3UTR, respectively. Single colonies of Agrobacterium transformed with these gene fragments into the TRV2 vector were grown overnight in $20 \mathrm{~mL}$ of YEP media containing rifampicin $(50 \mu \mathrm{g} / \mathrm{mL})$ and kanamycin $(50 \mu \mathrm{g} / \mathrm{mL})$. The transformed Agrobacterium was harvested by centrifugation at 4,000 rpm for 15 min at $4^{\circ} \mathrm{C}$, re-suspended to $0.4 \mathrm{~A}_{600 \mathrm{~nm}}$ in $10 \mathrm{mM} \mathrm{MgCl}$ with $150 \mu \mathrm{M}$ acetosyringone, and incubated at $22^{\circ} \mathrm{C}$ with shaking for $4 \mathrm{~h}$. A. tumefaciens transformed with TRV1 was adjusted to a concentration of $0.08 \mathrm{~A}_{600 \mathrm{~nm}}$ in $10 \mathrm{mM} \mathrm{MgCl}$ with $150 \mu \mathrm{M}$ acetosyringone and incubated at $22^{\circ} \mathrm{C}$ with shaking for $4 \mathrm{~h}$. A. tumefaciens transformed with TRV1 and A. tumefaciens transformed with TRV2:GFP, TRV2:CaPDS, TRV2:NMMP1-M, or TRV2:NMMP1-3UTR were mixed at 
a 1:1 ratio and then inoculated into the cotyledons of twoweek old $N$. benthamiana seedlings using an $1-\mathrm{mL}$ needleless syringe. At least 12 seedlings were used for silencing NMMP1. After 20 days of VIGS treatment, the silenced $N$. benthamiana were inoculated with Psta, Psta 11528, or PST1 at concentrations of $0.01,0.05$, and $0.1 \mathrm{OD}_{600 \mathrm{~mm}}$. All experiments were repeated at least twice.

Effect of NMMP1 over-expression or silencing on pathogen attack. The 6-week old leaves of $N$. benthamiana overexpressing or silencing $N M M P 1$ were inoculated with Psta 11528 or PstT1. The index of Psta 11528 or PST1 infection was determined based on the bacterial colony-forming units (CFUs) or by visual examination of necrotic regions, respectively. The CFUs were counted on 2 days of bacterial growth on the leaves. For the bacterial growth count, 0.9$\mathrm{cm}$ leaf discs were ground with $3 \mathrm{~mL}$ of $10 \mathrm{mM} \mathrm{MgCl}_{2}$ solution, and $10 \mu \mathrm{L}$ of diluted cells were layered onto King's B media with $100 \mu \mathrm{g} / \mathrm{mL}$ rifampicin. The CFU pathogen growth data were analyzed by Tukey's two-way analysis of variance using SAS version 6.12 (SAS Inc., Cary, NC, USA). The experiments were repeated at least three times.

\section{Results}

NMMP1 sequence analysis in $N$. benthamiana. The isolated $N M M P 1$ cDNA encodes a full-length protein with an open reading frame of 364 amino acid residues (Fig. 1), and the amino acid sequence was deposited in the NCBI database (accession no. ADD21635). NMMP1 shares 95\%, $82.9 \%$, and $82.2 \%$, amino acid identity with the matrixin genes from tobacco, tomato, and pepper, respectively (Fig. 2). Multiple sequence alignments of the $N M M P 1$ protein revealed that NMMP1 has a highly conserved Zn-containing catalytic protease domain for matrix metalloprotease. NMMP1 is predicted to have a cell surface glycosylphosphatidylinositol (GPI)-anchor site at amino acid 340 by the big-PI Predictor (Eisenhaber et al., 1999), suggesting attachment of the protein on the plasma membrane by the GPI-anchor.

Expression of $N M M P 1$ in response defense signaling molecules. $N M M P 1$ expression was detected in $N$. benthamiana treated with pathogens and various defense signaling molecules to understand the role of NMMP1. NMMP1 expression in leaves treated with Psta and PstT1 was determined for $24 \mathrm{~h}$ (Fig. 3). When leaves of $N$. benthamiana

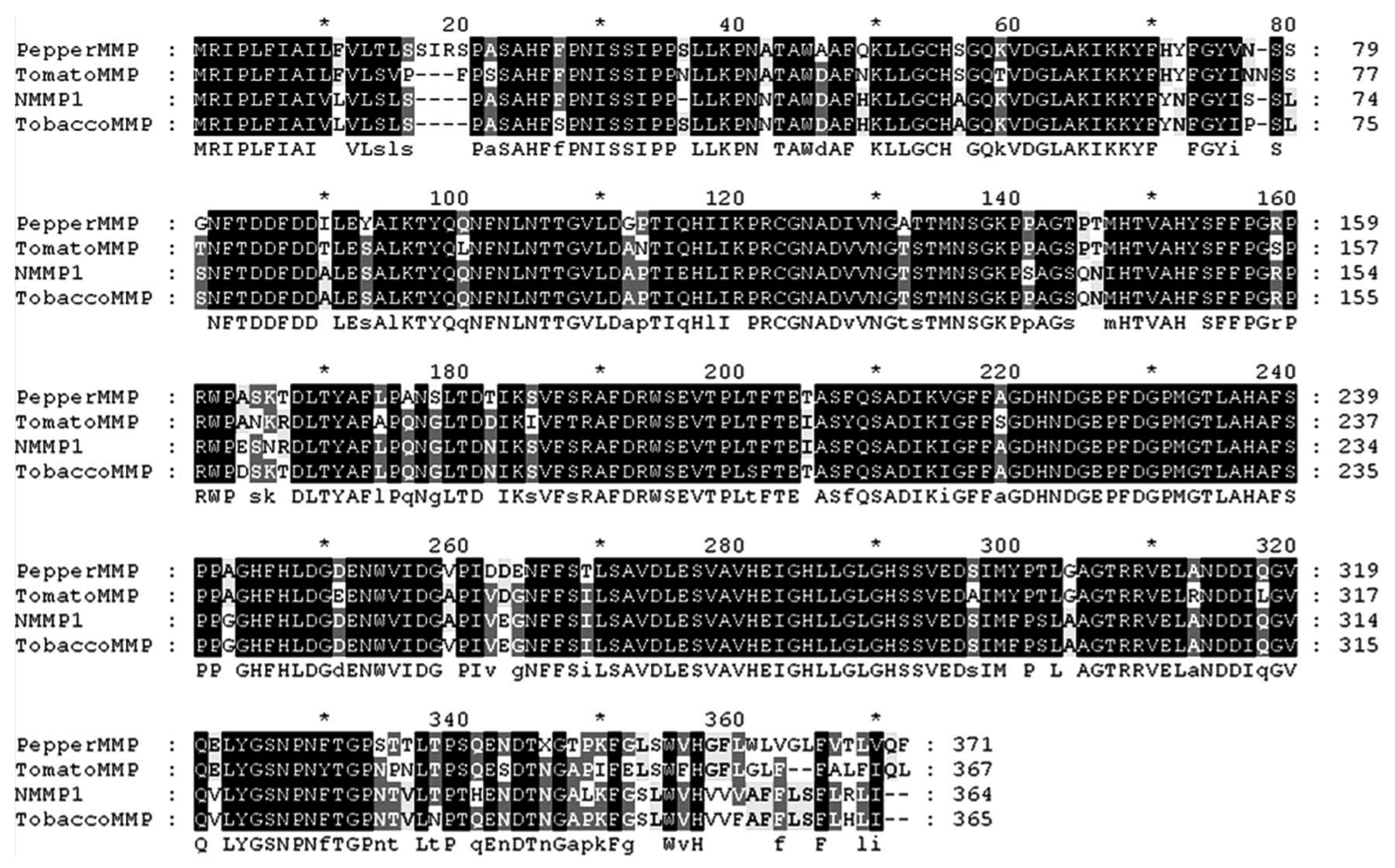

Fig. 2. Amino acid sequence alignment of the matrixin proteins of Nicotiana benthamiana, tobacco, tomato, and pepper using ClustalW. Translated sequences of $N$. benthamiana matrix metalloprotease 1 (NMMP1; NCBI ADD21635), tobacco matrixin gene (accession no. CAA77093), pepper matrixin EST contig (cacn16709), and tomato matrixin gene (NCBI accession no. AK322919) were aligned to compare the sequences. 


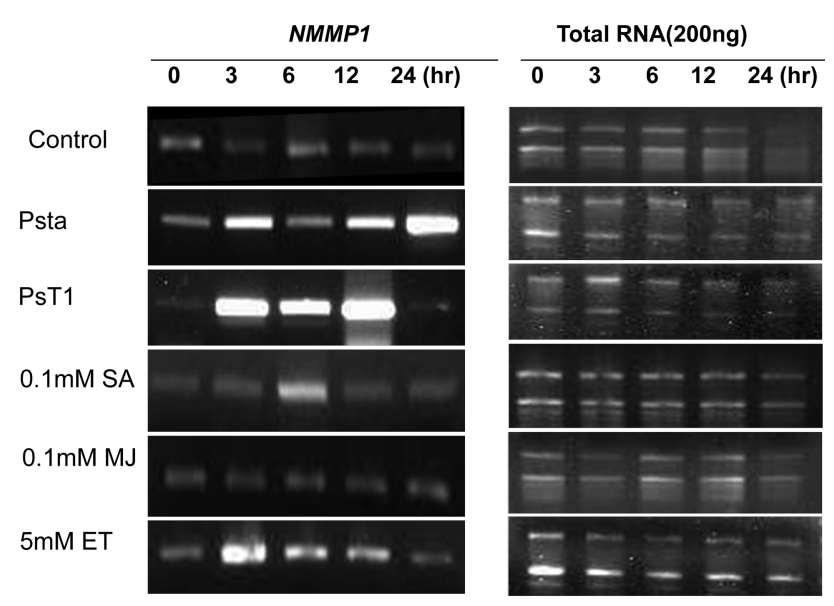

Fig. 3. Analysis of the Nicotiana benthamiana matrix metalloprotease $1(N M M P 1)$ expression patterns in response to biotic stresses and defense signal molecules. $N M M P 1$ expression in $N$. benthamiana was determined by semi-quantitative RT-PCR. $N$. benthamiana leaves were inoculated with $10 \mathrm{mM}$ MES, $10 \mathrm{mM}$ $\mathrm{MgCl}_{2}$ (control), a compatible pathogen Psuedomonas syringae pv. tabaci $(P s t a)$ at $0.1 \mathrm{OD}_{600 \mathrm{~nm}}$, an incompatible pathogen $P$. syringae pv. tomato $\mathrm{T} 1(P S T 1)$ at $0.1 \mathrm{OD}_{600 \mathrm{~nm}}$, or defense signaling molecules including $1 \mathrm{mM}$ salicylic acid (SA), $0.1 \mathrm{mM}$ methyl jasmonate (MJ), or $5 \mathrm{mM}$ ethephon (ET). RNA was isolated from the treated leaves, and semi-quantitative RT-PCR was performed using the RNA as the cDNA templates.

were treated with a compatible pathogen Psta and an incompatible pathogen $P S T 1$, the $N M M P 1$ expression levels increased significantly after $3 \mathrm{~h}$ of treatment. The NMMP1 expression levels in leaves treated with Psta decreased after $6 \mathrm{~h}$; however, the expression levels increased again after 12 $\mathrm{h}$ of treatment. The NMMP1 expression levels in leaves treated with PST1 increased significantly, but decreased after $24 \mathrm{~h}$, when the $N$. benthamiana cells were dying due to a hypersensitive response (HR).

To test which signal molecules regulate NMMP1 expression, $N$. benthamiana leaves were inoculated with defense signaling molecules, such as SA, MJ, and ET for ethylene (Fig. 3). Further characterization of NMMP1 gene expression after $24 \mathrm{~h}$ of defense signal molecule innoculation revealed that only ET highly induced NMMP1 up-regulation after $3 \mathrm{~h}$ of treatment.

Role of NMMP1 in $N$. benthamiana pathogen defense. The role of the NMMP1 gene in defense was investigated by employing transient $N M M P$ loverexpression or silencing in $N$. benthamiana and in plants infected with Psta 11528 or PST1. Transient NMMP1 over-expression in $N$. benthamiana was verified by semi-quantitative RT-PCR (Fig. 4a). After one day inoculation of Psta 11528, the control leaves had a 1.59 times greater number of CFUs than the leaves over-expressing NMMPl (Fig. 4b).
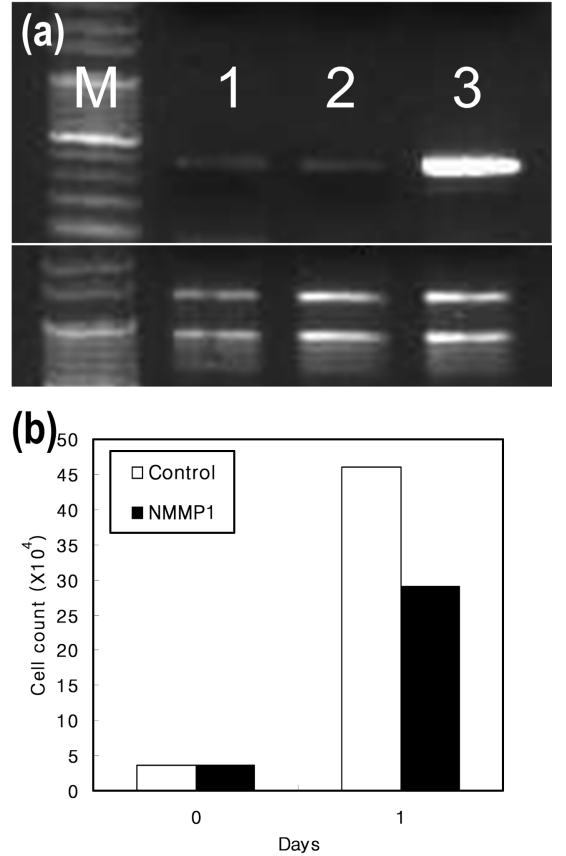

Fig. 4. Effect of Nicotiana benthamiana matrix metalloprotease 1 (NMMP1) overexpression on the growth of a compatible pathogen Psuedomonas syringae pv. tabaci 11528 (Psta 11528). (a) Semi-quantitative RT-PCR detecting NMMP1 expression levels in a leaf of wild-type $N$. benthamiana (lane 2), 23001 vector only-expressed $N$. benthamiana (lane 3), and NMMP1 over-expressed $N$. benthamiana (lane 4). Size markers (one kb plus markers) were loaded in lane 1. (b) Growth of Psta 11528 inoculated at $0.01 \mathrm{OD}_{600 \mathrm{~nm}}$ in 23001 vector-expressed or NMMP1 over-expressed leaves.

NMMP1 over-expressed leaves seemed to show faster HR symptoms in response to infiltration of the Pst 1 incompatible pathogen than control leaves inoculated with only the 23001 vector itself (data not shown); however, it was difficult to determine the exact time for induction of the HR symptoms.

The role of $N M M P 1$ in the pathogen defense response was further investigated by silencing NMMP1 using the VIGS technique. Two VIGS vectors were constructed; $N M M P 1-M$ containing the matrixin catalytic region and NMMP1-3UTR containing the 3' UTR. NMMP1-silenced $N$. benthamiana showed no significant morphological changes compared to wild type or GFP-silenced $N$. benthamiana. Semi-quantitative RT-PCR data showed that the NMMP1-silenced plants had reduced NMMP1 expression compared to the GFP-silenced control plants (Fig. 5a). When the growth of Psta 11528 was determined by counting CFUs from the pathogen infiltrated leaves, NMMP1silenced leaves infected with Psta 11528 had significantly higher numbers of CFUs than the control leaves after 2 days of infection (Fig. 5b). Visual inspection did not show any slower induction of the HR symptoms in NMMP1- 


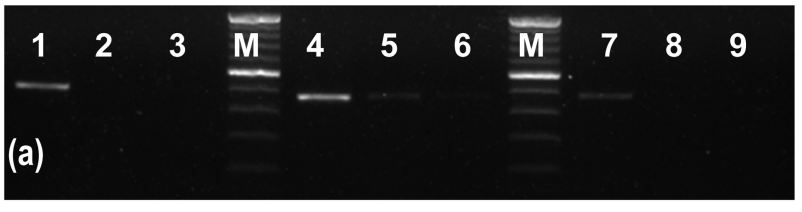

(b)

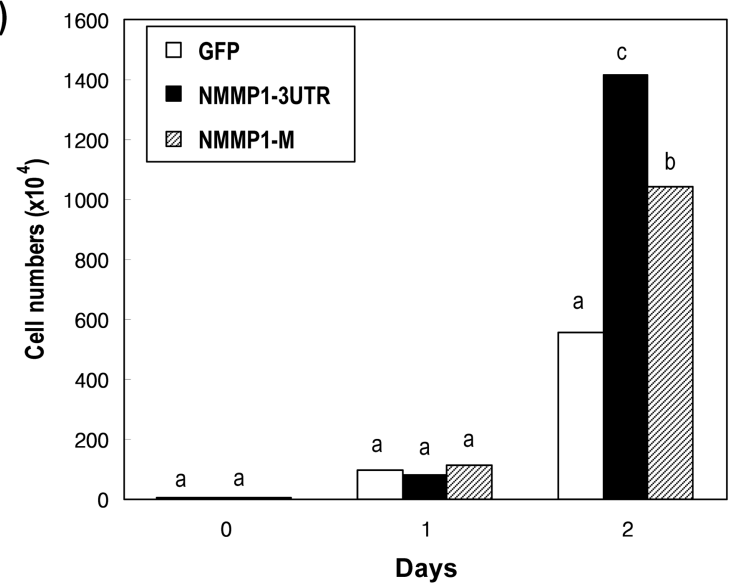

Fig. 5. Effect of Nicotiana benthamiana matrix metalloprotease 1 $(N M M P 1)$ silencing on the growth of a compatible pathogen Psuedomonas syringae pv. tabaci 11528 (Psta 11528). Two virusinduced gene silencing vectors $N M M P 1-M$ or $N M M P 1-3 U T R$ were constructed to silence the catalytic middle region or the $3^{\prime}$ untranslated region of $N M M P 1$, respectively. Leaves silenced with green fluorescent protein (control), NMMP1-M, or NMMP1$3 U T R$ were inoculated with Psta 11528, and colony forming units (CFUs) were counted over 2 days. (a) Semi-quantitative RT-PCR analysis showing $N M M P 1$ expression levels in $N$. benthamiana leaves under normal growth conditions (lane 1: control, lane 2: $N M M P 1-M$ silenced, lane 3: NMMP1-3UTR silenced), after 1 day of Psta 11528 inoculation (lane 4: control, lane 5: NMMP1$M$ silenced, lane 6: NMMP1-3UTR silenced), and after 2 days of Psta 11528 inoculation (lane 7: control, lane 8: NMMP1-M silenced, lane 9: NMMP1-3UTR silenced). $\mathrm{M}$ represents the loading of one $\mathrm{kb}$ plus marker. (b) Growth of Psta 11528 inoculated into the leaves of $G F P$-silenced or $N M M P 1$-silenced $N$. benthamiana. CFUs of Psta 11528 inoculated at $0.01 \mathrm{OD}_{600 \mathrm{~nm}}$ were counted after 2 days. The CFU pathogen growth was analyzed by Tukey's two-way analysis of variance using SAS. Values followed by different letters are significantly different $(p<0.05)$.

silenced plants than in the GFP-silenced control plants (data not shown).

\section{Discussion}

The ECM is a complex structural entity surrounding and supporting cells and is the boundary for plant pathogens and plant cell interactions. The roles of matrixins as determinant proteases of ECM structure have been studied for growth, development, and pathogenesis (Barett et al., 2004). However, the roles of plant MMPs in pathogen defense are unclear, although there has been speculation that MMPs are involved in plant growth, development, and defense responses (Golldack et al., 2002). We isolated the NMMP1 gene, which is the first time an ECM metalloprotease gene has been isolated in $N$. benthamiana. The NMMP1 gene has an open reading frame of 1,095 nucleotides; therefore, it encodes a 364 amino acid protein. As a protein predicted to be connected to the plasma membrane by a GPI anchor, the C-terminus of the mature NMMP1 protein is attached to glycosylphosphatidylinositol by posttranslational modification. The two fatty acids within the hydrophobic phosphatidyl-inositol group anchor the NMMP1 protein to the plasma membrane, so the NMMP1 protein remains attached to the exterior leaflet of the plasma membrane.

NMMP 1 was constitutively expressed at very low levels; however, it was rapidly up-regulated by compatible and incompatible pathogen infections. Using the transient overexpression technique, we increased NMMP1 gene expression levels by inoculating Agrobacterium with NMMP1 into the leaves of $N$. benthamiana. Successful NMMP1 over-expression decreased the growth of the Psta.11528 (Fig. 4c). In contrast to the over-expression experiments, silencing $N M M P 1$ in $N$. benthamiana using the VIGS technique resulted in significantly faster growth of Psta 11528 (Fig. 5b). We further investigated the defense signal molecules that regulate $N M M P$ lexpression and found the involvement of ET (Fig. 3). Other defense molecules, including SA and $\mathrm{MJ}$ did not change $N M M P$ lexpression levels, which coincided with previous reports of matrixin expression in other plant species (Liu et al., 2001; Schiermeyer et al., 2009). Only the ET treatment, the precursor of ethylene signal molecule, induced high expression of $N M M P 1$. These data strongly suggest that the newly isolated $N M M P 1$ gene is regulated by ethylene signaling, and that there is active involvement of the gene product in defense to reduce the spread of bacterial pathogens. The higher production of ethylene by pathogen attack induces the over-expression of $N M M P 1$, which might activate the defense systems in ECM.

A huge accumulation of evidence has implicated the involvement of proteases in pathogen defense. The NMMP1 in $N$. benthamiana is constitutively expressed in small amounts and secreted to ECM but attached to the plasma membrane. When $N$. benthamiana ages or is severely threatened by bacterial pathogens, overproduction of ethylene gas can trigger $N M M P 1$ expression. However, the involvement of $N M M P 1$ in aging was not evident in the $N M M P 1$-silenced $N$. benthamiana, suggesting that NMMP1 over-expression during senescence might not be directly correlated with aging. Identification of the NMMP1 target proteins in host plants for pathogen defense will be chall- 
enging to understand the function of NMMP1 in pathogen defense. Many GPI-anchored proteins are preferentially located in lipid rafts and released from the membrane by phospholipase $\mathrm{C}$ action, therefore, identifying the location of NMMP1 on the plasma membrane and the involvement of phospolipase $\mathrm{C}$ in NMMP1 release will be interesting work for the future.

\section{Acknowledgements}

This work was financially supported by the Yeungnam University Research Grants in 208-C-000-162 to K.-H. Baek.

\section{References}

Almeida, N. F., Yan, S. C., Lindeberg, M. D., Studholme, D. J., Schneider, D. J., Condon, B. F., Liu, H. J., Viana, C. J., Warren, A., Evans, C., Kemen, E., MacLean, D., Angot, A., Martin, G. B., Jones, J. D., Collmer, A., Setubal, J. C. and Vinatzer, B. A. 2009. A Draft genome sequence of Pseudomonas syringae pv. tomato $\mathrm{T} 1$ reveals a type III effector repertoire significantly divergent from that of Pseudomonas syringae pv. tomato DC3000. Mol. Plant-Microbe Interact. 22:52-62.

An, G. 1987. Binary Ti vectors for plant transformation and promoter analysis. Meth. Enzymol. 153:292-305.

Baek, K.-H. and Choi, D. 2008. Roles of plant proteases in pathogen defense. Plant Pathol. J. 24:367-487.

Barrett, A. J., Rawlings, N. D. and Woessner, J. F. eds. 2004. Handbook of proteolytic enzymes. Elservier Academic Press, London.

Chung, E., Seong, E., Kim, Y. C., Chung, E. J., Oh, S. K., Lee, S., Park, J. M., Joung, Y. H. and Choi, D. 2004. A method of high frequency virus-induced gene silencing in chili pepper (Capsicum annuum L. cv. Bukang). Mol. Cells 17:377-380.

Coffeen, W. C. and Wolpert, T. J. 2004. Purification and characterization of serine proteases that exhibit caspase-like activity and are associated with programmed cell death in Avena sativa. Plant Cell 16:857-873.

Combier, J. P., Vernié, T., De Billy, F., El Yahyaoui, F., Mathis, R. and Gamas, P. 2007. The MtMMPL1 early nodulin is a novel member of the matrix metalloendoproteinase family with a role in Medicago truncatula infection by Sinorhizobium meliloti. Plant Physiol. 144:703-716.

Delorme, V. G., McCabe, P. F., Kim, D. J. and Leaver, C. J. 2007. A matrix metalloproteinase gene is expressed at the boundary of senescence and programmed cell death in cucumber. Plant Physiol. 123:917-927.

Dreher, K. A. and Callis, J. 2000. Ubiquitin, hormones and biotic stress in plants. Ann. Bot. 9:787-822.

Eisenhaber, B., Bork, P. and Eisenhaber, F. 1999. Prediction of potential GPI-modification sites in proprotein sequences. $J$. Mol. Biol. 292:741-758.

García-Lorenzo, M., Sjödin, A., Jansson, S. and Funk, C. 2006. Protease gene families in Populus and Arabidopsis. BMC Plant Biol. 6:30.

Golldack, D., Popova, O. V. and Dietz, K. J. 2002. Mutation of the matrix metalloproteinase At2-MMP inhibits growth and causes late flowering and early senescence in Arabidopsis. $J$. Biol. Chem. 277:5541-5547.

Graham, I. A., Xiong, J. and Gillikin, J. W. 1991. Purification and developmental analysis of a metalloproteinase from the leaves of Glycine max. Plant Physiol. 97:786-792.

Kapila, J., De Rycke, R., Van Montagu, M. and Angenon, G. 1997. An Agrobacterium-mediated transient gene expression system for intact leaves. Plant Sci. 122:101-108.

Liu, Y., Dammann, C. and Bhattacharyya, M. K. 2001. The matrix metalloproteinase gene GmMMP2 is activated in response to pathogenic infections in soybean. Plant Physiol. 127:1788-1797.

Liu, Y., Schiff, M. and Dinesh-Kumar S. P. 2002. Virus-induced gene silencing in tomato. Plant J. 31:777-786.

Maidment, J. M., Moore, D., Murphy, G. P., Murphy, G. and Clark, I. M. 1999. Matrix metalloproteinase homologues from Arabidopsis thaliana. J. Biol. Chem. 274:34706-34710.

McGeehan, G.., Burkhart, W., Anderegg, R., Becherer, J. D., Gillikin, J. W. and Graham, J. S. 1992. Sequencing and characterization of the soybean leaf metalloproteinase: Structural and functional similarity to the matrix metalloproteinase family. Plant Physiol. 99:1179-1183.

Nagase, H. and Woessner, J. F. Jr. 1999. Matrix metalloproteinases. J. Biol. Chem. 274:21491-21494.

Pak, J. H., Liu, C. Y., Huangpu, J. and Graham, J. S. 1997. Construction and characterization of the soybean leaf metalloproteinase cDNA. FEBS Lett. 404:283-288.

Ratnaparkhe, S. M., Egertsdotter, E. M. U. and Flinn, B. S. 2009. Identification and characterization of a matrix metalloproteinase (Pta1-MMP) expressed during Loblolly pine (Pinus taeda) seed development, germination completion, and early seedling establishment. Planta 230:339-354.

Rawlings, N. D., Barrett, A. J. and Bateman, A. 2010. MEROPS: the peptidase database. Nucl. Acids Res. 38:D227-D233.

Roberts, K. 1994. The plant extracellular matrix: in a new expansive mood. Curr. Opin. Cell Biol. 6:688-694.

Schiermeyer, A., Hartenstein, H., Mandal, M. K., Otte, B., Wahner, V. and Schillberg, S. 2009. A membrane-bound matrixmetalloproteinase from Nicotiana tabacum cv. BY-2 is induced by bacterial pathogens. BMC Plant Biol. 9:83.

van der Hoorn, R. A. L. and Jones, J. D. 2004. The plant proteolytic machinery and its role in defence. Curr. Opin. Plant. Biol. 7:400-407.

van der Hoorn R. A. L. 2008. Plant proteases: From phenotypes to molecular mechanisms. Annu. Rev. Plant Biol. 59:191-223. 